\title{
Erratum
}

\section{Erratum: Hallum et al., "Altered Balance of Receptive Field Excitation and Suppression in Visual Cortex of Amblyopic Macaque Monkeys"}

In the article "Altered Balance of Receptive Field Excitation and Suppression in Visual Cortex of Amblyopic Macaque Monkeys" by Luke E. Hallum, Christophe Shooner, Romesh D. Kumbhani, Jenna G. Kelly, Virginia Garcia-Marin, Najib J. Majaj, J. Anthony Movshon, and Lynne Kiorpes, which appeared on pages 8216-8226 of the August 23, 2017 issue, the minus signs were accidentally left off Figure 6 during production. This correction does not affect the conclusions of the paper. Figure 6 has been corrected on the online PDF version and displayed below.

A

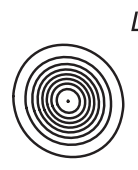

LE RE

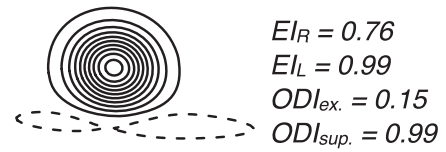

B
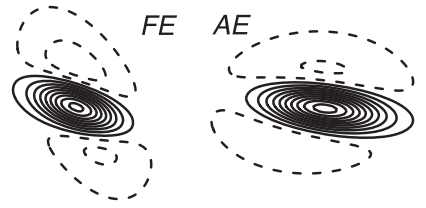

$E I_{F}=0.01$

$E I_{A}=-0.15$

$O D I_{e}=-0.21$

-..

$O D I_{s}=-0.08$

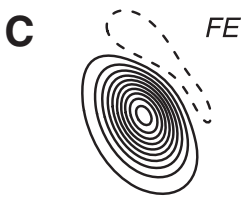

$A E$

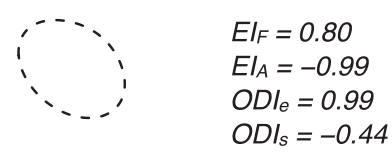

D

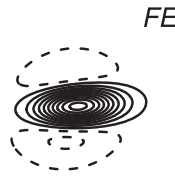

$A E$

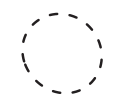

$E I_{F}=0.35$

$E I_{A}=-0.67$

$O D I_{e}=0.85$

$O D I_{s}=0.10$

1 carrier cycle

Figure 6. 